\title{
Argumentação e Desenvolvimento do Pensamento Reflexivo
}

\author{
Argumentation and Development of Reflective Thinking
}

\author{
Selma Leitão* \\ Universidade Federal de Pernambuco, Recife, Brasil
}

\begin{abstract}
Resumo
O objetivo central do presente ar tigo é oferecer uma perspectiva a partir da qual as relações entre argumentação e reflexão podem ser investigadas. O argumento central proposto é que os mesmos mecanismos semióticodialógicos que constituem a argumentação (justificação de pontos de vista, consideração de objeções e reação a elementos contrários) são igualmente efetivos em deslocar o pensamento do indivíduo para um plano reflexivo (metacognitivo). A produção destas ações discursivas reorienta o pensamento do indivíduo do objeto sobre o qual argumenta para o exame das bases e limites de suas próprias concepções sobre aquele objeto. Tal reorientação institui o pensamento do próprio indivíduo como objeto de reflexão. Na segunda parte do artigo, uma análise de fragmentos de argumentação produzida por crianças em sala de aula ilustra a forma como a perspective proposta pode ser utilizada na investigação do desenvolvimento de processos auto-regulados de reflexão.
\end{abstract}

Palavras-chave: Argumentação; linguagem e cognição; metacognição; reflexão.

\begin{abstract}
The main goal of this article is to offer a perspective from which the relations between argumentation and reflection can be investigated. The main argument proposed is that the same semiotic-dialogic mechanism that constitutes argumentation (supporting a view with reasons, considering objections and responding to opposition) has a built-in capacity to place the arguer's thinking in a metacognitive framework. Together, they are effective in orienting the thinking a person does towards examining the bases and limits of his/her own thoughts. They do so by introducing into the person's psychological field a new object for reflection - the arguer's own thoughts. At the second section of the article, the analysis of some fragments of children's argumentation produced in classroom illustrates how the framework proposed can be used in investigating the development of self-regulated reflection.

Keywords: Argumentation; language and cognition; metacognition; reflection.
\end{abstract}

O presente artigo focaliza a argumentação enquanto recurso semiótico-discursivo de mediação no desenvolvimento do pensamento reflexivo. A diversidade de sentidos que se pode atribuir aos termos argumentação e refle$x$ ão exige que se especifique, já na introdução do presente texto, que sentidos se tem em vista no emprego destes termos. A argumentação é aqui entendida como uma atividade de natureza discursiva e social que se realiza pela defesa de pontos de vista e a consideração de objeções e perspectivas alternativas, com o objetivo último de aumentar - ou reduzir - a aceitabilidade dos pontos de vista em questão (Van Eemeren et al., 1996). Tomadas em conjunto, a defesa de pontos de vista e a consideração de idéias alternativas criam, no discurso, um processo de negociação que possibilita o manejo de divergências entre concepções a respeito de fenômenos do mundo (físico ou so-

* Endereço para correspondência: Universidade Federal de Pernambuco, Pós-Graduação em Psicologia Cognitiva, $\mathrm{CFCH}, 8^{\circ}$. Andar, Cidade Universitária, Recife, PE, 50670901. E-mail: selma_leitao2001@yahoo.com

A autora agradece ao $\mathrm{CNPq}$ o apoio recebido para realização deste trabalho na forma de bolsa de produtividade em pesquisa cial). Este processo de negociação de diferenças de perspectivas confere à argumentação um potencial epistêmico que a institui como recurso privilegiado de constituição do conhecimento e - argumenta-se no presente artigo de desenvolvimento do pensamento reflexivo.

A expressão pensamento reflexivo, como é aqui empregada, designa um processo auto-regulador do pensamento, processo este que se constitui quando um indivíduo toma suas próprias concepções sobre fenômenos do mundo (conhecimento) como objeto de pensamento e considera as bases em que estas se apóiam e os limites que as restringem. O pensamento reflexivo, assim definido, caracterizase, portanto, como um processo de natureza eminentemente metacognitiva (Leitão, 2002, no prelo).

A ênfase sobre os elos genéticos entre argumentação e reflexão não é nova na literatura psicológica. Piaget e Vygotsky, os dois pensadores que, provavelmente, maior influência exerceram sobre a psicologia do desenvolvimento produzida no último século, ambos viram a reflexão como um processo intrinsecamente ligado a formas argumentativas de comunicação (Piaget, 1923/1999; Vygotsky, 1931/1995). Entretanto, os modos como um e outro conceituaram o vínculo entre argumentação e reflexão foram, previsivelmente, radicalmente diversos. Anco- 
rado numa perspectiva que subordina a linguagem à estruturação do pensamento, Piaget via na argumentação infantil um lócus privilegiado de explicitação e externalização de níveis de desenvolvimento lógico da criança. Vygotsky, por outro lado, partindo de uma perspectiva que concede à linguagem um papel constitutivo em relação ao psiquismo, critica a proposta piagetiana e inverte a relação por ele sugerida. Para Vygotsky, longe de explicitar uma reflexão previamente constituída, é o engajamento em argumentação que possibilitará o desenvolvimento da reflexão. Embora ambos os autores tenham reconhecido as relações entre argumentação e reflexão, não se encontra em seus trabalhos qualquer teorização que especifique características e mecanismos, inerentes à argumentação, que a tornariam um recurso discursivo privilegiado em relação ao desenvolvimento da reflexão. Tanto quanto é do meu conhecimento, tampouco na literatura produzida em conexão com as proposições teóricas dos dois autores se encontram trabalhos que explorem a gênese do pensamento reflexivo em suas possíveis relações com a gênese de condutas argumentativas. A perspectiva que aqui se apresenta busca contribuir nesta direção.

Antes, porém, de explicitar os elementos específicos da perspectiva proposta, uma breve revisão dos pressupostos que a fundamentam é apresentada. Esse quadro de referência, axiomaticamente assumido, é formado por dois componentes principais: um marco epistemológico que explicita concepções sobre linguagem, cognição e suas inter-relações e um componente teórico que explicita pressupostos sobre o desenvolvimento das funções psicológicas estritamente humanas.

\section{Cognição e Linguagem}

O ponto de partida, axiomaticamente assumido na presente perspectiva, é que formas estritamente humanas de cognição e outros funcionamentos psicológicos conscientes surgem no contexto de relações dialógicas e são de natureza necessariamente sociossemiótica - mediadas pela linguagem e outros recursos semióticos histórica e culturalmente constituídos (Bakhtin \& Volochinov, 1929-1930/ 1995; Mead, 1934/1972; Vygotsky, 1931/1995, 1934/ 2001). Esta perspectiva distancia-se de concepções ditas individualistas sobre a natureza da cognição humana notadamente as cognitivistas - segundo as quais a construção do conhecimento e o desenvolvimento cognitivo humanos são conceituados como processos que se realizam primordialmente no plano intrapsicológico. O papel aí conferido à linguagem é o de um recurso que possibilita a externalização de cognições previamente constituídas no plano interno e viabiliza a comunicação entre os indivíduos (ver Linnell, 1998 para caracterização e crítica a este paradigma monológico na psicologia).

Em contraste, concepções dialógicas sobre as relações entre mundo, cognição e linguagem enfatizam a relação (mediada pela linguagem) do organismo com o ambiente físico e social em que vive como condição primeira para a constituição dos processos que possibilitam a comunicação e o conhecimento humanos. Enquanto perspectiva epistemológica, tais concepções se apóiam fortemente nos escritos de autores como Mead, Vygotsky, Bakhtin, Volochinov e outros da chamada "era de ouro da psicologia e da semiótica soviéticas" (Rommetveit, 1992, p. 24). Comum a todos estes estudiosos é a visão de que as atividades mentais e de comunicação humana são sociais e dialógicas em sua gênese, estrutura e funcionamento. $\mathrm{O}$ entendimento da cognição como processo dialógico exige, entretanto, que se supere a concepção estrita que identifica diálogo com interação verbal face a face e se focalizem as relações mundo-pensamento, sujeito-sujeito, enunciado-enunciado, constituídas na linguagem, seja esta produzida em situações de interação face a face, ou não. Nesta perspectiva, os processos cognitivos e comunicativos em que se engaja cada indivíduo são vistos como inerentemente duais, como parte de uma corrente ininterrupta de cognições e comunicações histórica e culturalmente constituídas. Cada ato de cognição ou comunicação - como evento único e, portanto, não repetível - é entendido como uma resposta, uma tomada de posição valorativa diante de outras ações que o antecederam. Tal ato, por sua vez, antecipa uma resposta, ou seja, convoca uma tomada de posição em reação ao ato já realizado.

A ênfase na gênese social e na natureza dialógica dos processos mentais concede um lugar central a recursos semióticos originalmente constituídos para finalidades sociais - a linguagem, em especial - os quais, quando ativamente reconstruídos no plano intrapsíquico, se tornam 'blocos de construção' da atividade mental dos indivíduos. "A realidade do psiquismo interior é a do signo. Sem material semiótico não se pode falar em psiquismo" (Bakhtin \& Volochinov, 1929-1930/1995, p. 49). Uma implicação imediata da aceitação desta premissa é que a cognição e outros processos psicológicos só podem ser adequadamente compreendidos quando se examina a natureza dos recursos simbólicos e processos dialógicos a partir dos quais os processos mentais são constituídos. A interdependência entre cognição e linguagem, estabelecida no plano teórico, impede que, no plano metodológico, esses processos sejam isoladamente estudados. Reconhecer a natureza essencialmente sociossemiótica do psiquismo implica ainda admitir a existência de estreitas relações entre características dos processos psicológicos que emergem em meio às experiências sociais do indivíduo e propriedades específicas dos recursos semióticos envolvidos na gênese de tais processos. As propriedades dos recursos semióticos usados configuram e se refletem nos processos que deles emergem (Vygotsky, 1931/1995).

\section{Sobre a Constituição de Funções Psíquicas Especificamente Humanas}

A ancoragem psicológica da presente proposta é dada por idéias propostas no âmbito das perspectivas histórico-culturais sobre o desenvolvimento humano as quais buscam explicar a gênese dos processos cognitivos a partir da apropriação, pela criança, de recursos materiais e simbólicos disponibilizados pela cultura (Valsiner \& Van der Veer, 200O; Vygotsky, 1931/1995; Wertsch, 1988; Wertsch, 
Del Río \& Alvarez, 1995). Apresentações, expansões e críticas desta e a esta formulação aparecem num extenso número de publicações produzidas nas últimas décadas (ver, por ex., trabalhos listados em Vygotsky, 1934/2001) não havendo aqui qualquer propósito ou possibilidade de retomá-las em detalhe. Cabe, entretanto, assinalar algumas noções-chave, que se conectam diretamente à perspectiva aqui focalizada.

\section{Natureza Semiótica do Psiquismo}

O papel decisivo do signo na constituição dos processos cognitivos se torna particularmente evidente a partir da distinção entre processos psíquicos elementares e superiores, crítica no pensamento vygotskiano. Enquanto os primeiros surgem como produto da evolução biológica da espécie e, portanto, podem ser observados no indivíduo humano já no início da vida, os segundos têm estatuto eminentemente social. Resultam do desenvolvimento histórico do comportamento nos planos filo e ontogenético e dependem, em sua origem, da mediação da linguagem e de outros recursos simbólicos da cultura. Os processos elementares dotam o recém-nascido com a capacidade de agir sobre o ambiente de uma forma direta (i-mediata), não consciente, regulada por estímulos externos que surgem no ambiente. Aí se incluem formas involuntárias de pensamento (não-verbal, ligado à resolução de problemas simples), percepção, atenção, memória.

Os processos psíquicos superiores, em contraste, somente vêm a existir a partir do acesso e apropriação, pela criança, de recursos materiais e simbólicos culturalmente desenvolvidos. Tais processos possibilitam ao indivíduo, formas indiretas (mediadas) e auto-reguladas de ação sobre o mundo. Instrumentos e signos são os dois tipos de mediadores propostos nos escritos de Vygotsky. Enquanto os primeiros orientam e regulam a ação humana sobre objetos do mundo, os segundos se orientam para a regulação do psiquismo - o próprio e os de outros (Vygotsky, 1931/1995). A apropriação do signo transforma radicalmente a natureza do funcionamento psicológico do indivíduo. Seu uso amplia as possibilidades de ação da mente humana dotando o indivíduo de recursos que lhe permitem, por exemplo, regular a própria atenção e a de outros, reter e recordar uma quantidade praticamente infinita de estímulos, etc.

Entretanto, é, sobretudo, a forma como os recursos semióticos (a linguagem em particular) equipam o indivíduo com recursos para construir, organizar, significar e interpretar a realidade, que o impacto da mediação semiótica é mais radicalmente manifesto. De acordo com esta perspectiva, o acesso e a conceituação dos diferentes objetos, eventos e situações do mundo se realizam como formas de interpretação possibilitadas pela linguagem; como "leituras" da realidade que se materializam nos variados gêneros de discurso que circulam socialmente. Os processos de significação e interpretação do mundo surgem, portanto, como formas externalizadas, materializados numa gama de discursos histórica e culturalmente produzidos e socialmente disponibilizados. Somente quan- do estabelecidos externamente, no plano interpessoal de funcionamento psicológico dos indivíduos, podem ser ativamente (re)construídos no plano intrapessoal. Uma vez aí reconstruídos, tornam-se meios de conhecimento, recursos de conceituação da realidade (Medvedev, 1928/ 1985).

A posse destes recursos sígnicos transforma decisivamente a relação homem-mundo. É ante um mundo interpretado, "concebido como sendo de um certo tipo" (Bakhurst, 2002, p. 236), que o indivíduo se posiciona. Mais ainda: o domínio dos variados gêneros discursivos dota o indivíduo de recursos organizadores do pensamento permitindo-lhe que sua ação (de linguagem ou não) seja pensada a partir de certos fins, abrindo, portanto, caminho para o surgimento das formas auto-reguladas e conscientes de funcionamento psicológico que caracterizam as funções psíquicas superiores.

\section{Linguagem e Regulação}

A regulação dos processos cognoscitivos (a possibilidade de planejar, organizar e estruturar as próprias ações e as de outros) longe de ser possibilidade garantida $a$ priori, é algo que se constitui no decurso do desenvolvimento lingüístico-cognitivo dos indivíduos, em que pese o valor constitutivo da linguagem. Segundo proposto por Vygotsky, é nas vicissitudes da internalização da linguagem externa (socialmente orientada para a comunicação com o outro) e conseqüente constituição da linguagem interior (constitutiva do mental) que se pode traçar a origem primeira dos processos auto-reguladores. O surgimento da fala egocêntrica é momento crítico nesta transformação externo-interno - é acontecimento que marca, por excelência, "a emergência de uma nova função, auto-reguladora, reflexiva, da linguagem” (Morato, 1996, p. 47).

A transformação do funcionamento cognitivo de formas imediatas e involuntárias para formas mediadas e autoreguladas é sintetizada por Morato (1996) em quatro grandes etapas. Na primeira, a ação da criança se constitui a partir das possibilidades de resposta ao meio externo de que é biologicamente dotada; estímulos do meio externo controlam sua ação. Posteriormente, a criança se tornará capaz de usar signos externos como recursos auxiliadores de sua ação no ambiente. A experiência da criança com a linguagem, nesta segunda fase, é a experiência com um signo auxiliar que liberta sua ação do controle anteriormente exercido pelos estímulos externos. A terceira fase será marcada pela possibilidade da criança regular sua própria ação, embora a concorrência de estímulos externos seja ainda necessária. Na quarta e última etapa, finalmente, as relações entre estímulos, signos e ações, já internalizadas, tornam desnecessário o apelo a estímulos intermediários. Pelo que se pode depreender do sumário acima, a passagem da regulação externa à auto-regulação é aí focalizada em termos que se aplicam à regulação exercida pela linguagem sobre variadas formas de ação. À presente perspectiva interessa considerar, sobretudo, formas de regulação que a linguagem exerce sobre as pró- 
prias ações de linguagem que o indivíduo realiza. A característica de auto-referencialidade da linguagem - ela fala de si mesma - possibilita este movimento auto-regulador.

Um dos pontos centrais da perspectiva que será proposta em seguida é que os movimentos cognitivodiscursivos de justificar um ponto de vista e responder a posições alternativas - que caracterizam e constituem os gêneros argumentativos - exercem um efeito regulador específico sobre a atividade cognitivo-discursiva do indivíduo (note-se que à expressão gêneros argumentativos é dada aqui uma acepção generalizante que inclui quaisquer gêneros que incorporem, de forma implícita ou explícita, defesa de pontos de vista e consideração de perspectivas contrárias). Para justificar um ponto de vista é inevitável que o indivíduo se volte sobre seu próprio discurso e sobre ele elabore - neste sentido se pode dizer então que o discurso 'fala sobre si mesmo'. De modo semelhante, responder à oposição eventualmente levantada em relação a este ponto de vista implica voltar-se sobre o próprio discurso e considerar limites e restrições (postos em evidência pela oposição) ao que foi dito. Enquanto movimentos discursivos que levam o indivíduo que os produz a focalizar seu próprio discurso - por conseguinte, seu próprio pensamento - a eles se atribui um papel constitutivo na gênese do pensamento reflexivo.

\section{Argumentação e Reflexão: Perspectiva Proposta}

Teóricos e pesquisadores que investigam o funcionamento da cognição humana freqüentemente diferenciam processos cognitivos envolvidos na conceituação de objetos e fenômenos do mundo, de processos, de natureza metacognitiva, em que o indivíduo se engaja quando reflete sobre sua própria conceituação daqueles objetos e fenômenos (Flavell, 1987; Kuhn, 2000; Martí, 1995). Diferenças expressivas entre concepções de linguagem e marcos epistemológicos subjacentes àquelas propostas e à presente perspectiva impedem que este paralelo seja levado mais adiante. Retém-se, no entanto, como ponto de partida para a proposta aqui apresentada, a diferenciação entre esses dois níveis de funcionamento psicológico.

A primeira tese que aqui se propõe é que "pensar sobre o mundo" (fazer afirmações sobre, conceituá-lo) e "pensar sobre as próprias concepções a respeito do mundo" remetem a diferentes níveis de semiotização do pensamento humano (Leitão, 2002). No primeiro nível, idéias/afirmações elaboradas ou evocadas pelo indivíduo são vistas como recursos de natureza sígnica que lhe possibilitam "fazer sentido" do mundo em que vive. No segundo nível de semiotização, diferentemente, as concepções elaboradas (no primeiro nível) tornam-se, elas próprias, alvo de análise e avaliação. A passagem do primeiro para o segundo nível demanda o emprego de recursos semióticos de segunda ordem - "afirmações sobre afirmações" - que possibilitam ao indivíduo refletir sobre as próprias idéias que elabora. A segunda tese proposta é que os movimentos argumentativo-discursivos de defesa de pontos de vista e consideração de perspectivas contrárias, ao mesmo tempo em que constituem a argumentação, equipam os participantes com um recurso semiótico de segunda ordem que possibilita a passagem do pensamento do primeiro para o segundo nível de semiose acima definidos.

\section{Mecanismos Argumentativos na Passagem da Cognição à Metacognição}

A terceira idéia proposta é que realizar as ações discursivas que constituem a argumentação (justificação de pontos de vista e consideração e resposta a posições contrárias) implica instituir o próprio pensamento como objeto de reflexão. A justificação de um ponto de vista exige que o indivíduo reoriente sua atenção do objeto (fenômeno, situação) ao qual o ponto de vista se refere e focalize as bases em que apóia suas afirmações/cognições sobre aquele objeto. De modo semelhante, considerar e responder a oposição exige que o indivíduo reoriente sua atenção do objeto sobre o qual argumenta e focalize a sustentabilidade e os limites de suas afirmações (postos em evidência pela contra-argumentação). Em ambos os casos, o deslocamento do foco da atenção do indivíduo implica uma diferenciação nos seus processos de pensamento. A partir deste deslocamento, idéias/concepções que o indivíduo formula sobre objetos do mundo são, elas próprias, instituídas como (novos) objetos para sua reflexão.

Finalmente, a quarta e última tese proposta é que a propriedade da argumentação que a torna um mediador eficaz na diferenciação dos níveis de semiotização do pensamento humano é a sua organização dialógico-dialética. O confronto com oposição é aqui definido como um mecanismo semiótico-dialógico que possibilita deslocar o pensamento do primeiro para o segundo nível de semiose.

\section{Auto-argumentação como Reflexão}

O metaprocesso que possibilita ao indivíduo refletir sobre bases e limites de suas próprias concepções sobre o mundo é aqui conceituado como um processo de argumentação dirigida para posições assumidas pelo próprio argumentador, ou auto-argumentação. Fala-se de auto-argumentação sempre que um indivíduo age como proponente e crítico (oponente) do mesmo argumento.

Três atributos básicos definem a auto-argumentação: dialogicidade, dialeticidade e reflexividade. A dialogicidade captura a coexistência de múltiplas vozes, múltiplas instâncias de enunciação que constituem e alimentam a autoargumentação. Em outras palavras, esse atributo captura a plurivocalidade constitutiva da linguagem e do pensamento humanos, conceito angular numa abordagem dialógica da linguagem (Bakhtin \& Volochinov, 1929-1930/ 1995). A dialeticidade, por sua vez, captura a forma constitutiva e específica com que a divergência entre posições se manifesta na argumentação - na argumentação a divergência é abertamente manifesta e gera um processo de negociação. A existência (percepção) de oposição entre perspectivas é vista como pré-requisito pragmático para que a argumentação se constitua (Van Eemeren et al., 1996). A tensão entre pontos de vista desencadeia no indivíduo um movimento auto-regulador que orienta seus 
movimentos discursivos para a busca de superação (não necessariamente resolução ou consenso) da tensão criada. Entretanto, uma vez que a uma afirmação é sempre possível opor uma contra-afirmação (Billig, 1987), esse movimento auto-regulador permanece, por definição, inconcluso. Finalmente, o prefixo auto- na expressão autoargumentação captura a existência de uma relação reflexiva entre o indivíduo que pensa/fala e o objeto de seu pensamento/discurso. Definir a existência de uma relação reflexiva entre dois fenômenos significa assumir que, embora se possa conceituar cada um deles em seus próprios termos, os dois estão de tal modo implicados que nenhum deles pode ser analisado sem que se pressuponha o outro (Linnell, 1998). Na abordagem aqui proposta, a reflexividade é entendida como uma propriedade básica que interconecta o indivíduo que pensa e o objeto de seu pensamento.

Para ilustrar como esta perspectiva teórica pode ser empiricamente investigada, uma análise de argumentação produzida em sala de aula é apresentada na seção seguinte. O propósito do estudo empírico realizado foi analisar a forma como ações verbais de alunos engajados em argumentação durante uma atividade de sala de aula regulam o pensamento dos mesmos levando-os a formas auto-reguladas de reflexão que lhes permitem considerar as bases e limites do conhecimento que eles mesmos produzem.

\section{Método}

Os dados analisados nesta seção são transcrições de registros em vídeo de uma discussão sobre o tema "Escravidão no tempo colonial" realizada como atividade curricular da disciplina História na quinta série do Ensino Fundamental de uma escola da rede particular (os dados citados integram Banco de Dados do NupArg - Núcleo de Pesquisa da Argumentação da Pós-Graduação em Psicologia Cognitiva da Universidade Federal de Pernambuco (UFPE), que funciona sob coordenação da autora). Da discussão analisada participaram 15 alunos que, após receberem orientação da professora, trabalhavam em uma atividade de grupo sem a presença da mesma. O deflagrador da argumentação analisada foi uma solicitação prévia da professora para que os alunos discutissem um conjunto de afirmações extraídas de fragmentos de textos retirados do próprio livro didático adotado pela escola para a disciplina de história. Para auxiliar na discussão, algumas perguntas foram dadas às crianças juntamente com a instrução de que buscassem chegar a uma resposta consensual para as mesmas (por exemplo: o que você acha que o autor está querendo dizer com esta frase? Você concorda ou discorda? Se concorda, por quê?).

\section{Procedimento e Objetivo da Análise}

A análise dos dados foi realizada nos níveis micro e macroanalítico. Na primeira fase da microanálise, o objetivo foi identificar os movimentos argumentativos realizados pelos participantes e, inerentes a estes, mecanismos discursivos que os induzem à reflexão sobre seus próprios argumentos. $\mathrm{Na}$ fase seguinte buscou-se identificar diferentes modos da regulação discursiva a partir dos quais a reflexão realizada pelos alunos foi gerada. Dois modos de regulação foram considerados: regulação por outro e autoregulação. Finalmente, com a terceira e última fase do processo de análise buscou-se investigar em que medida o engajamento em argumentação favoreceria a adoção, pelos participantes, de formas auto-reguladas de reflexão. Para tanto, uma segunda escala de tempo foi tomada como base de análise - a constituída pelo conjunto total dos movimentos discursivos realizados no curso da aula focalizada (macroanálise). A hipótese levantada foi a de que inicialmente as crianças tenderiam a se engajar em movimentos reflexivos a partir de demandas comunicativas de outros, sendo tal padrão posteriormente modificado em direção à reflexão auto-regulada.

Identificação de Movimentos Argumentativos: os procedimentos adotados para identificação de elementos argumentativos nas falas das crianças se baseiam na unidade de análise proposta em (Leitão, 2000, 2001) a qual é constituída por três elementos básicos: o primeiro elemento - o argumento - é formado por um ponto de vista seguido ou antecipado por um elemento que lhe dá suporte, a justificativa. No plano epistêmico (relativo ao processo de construção do conhecimento inerente à argumentação), o argumento explicita a concepção atual do falante sobre o tópico em discussão. O segundo elemento - contra-argumento - é aqui definido num sentido abrangente que inclui qualquer enunciado que levanta dúvidas, objeções e/ ou críticas a um argumento e que tem como efeito a redução da possibilidade de sua aceitação. O contra-argumento explicita e remete a possibilidades alternativas de entendimento do tópico focalizado e traz para a argumentação um elemento de oposição indispensável para que a mesma se constitua. Com o terceiro e último elemento - a resposta - torna-se possível capturar a reação do proponente de um argumento à oposição emergente. Ressaltase neste terceiro e último elemento o caráter eminentemente avaliativo. Responder implica avaliar a sustentabilidade de argumentos formulados à luz de restrições trazidas pela contra-argumentação. Do ponto de vista epistêmico, é a análise da resposta à oposição que permite capturar possíveis transformações nas concepções inicialmente formuladas pelos participantes. Juntos, os elementos acima definidos constituem o que se considera a unidade mínima de análise a partir da qual a reflexão, no sentido definido no presente trabalho, pode ser capturada.

Note-se que o "diálogo" que se estabelece no discurso entre argumento, contra-argumento e resposta pode ser gerado a partir de enunciados produzidos tanto por diferentes indivíduos como por um único argumentador que assume, simultaneamente, os papéis de proponente e oponente em relação a um mesmo ponto de vista (autoargumentação). No último caso, os movimentos contraargumentativos correspondem a antecipações, da parte do argumentador, de possíveis oposições ao seu próprio argumento. 
Identificação de Modos de Regulação: como dito anteriormente, para fins analíticos foram considerados diferentes modos de regulação a partir dos quais a reflexão pode ser gerada. Na regulação-por-outro, como o próprio nome o sugere, a ação verbal de uma outra pessoa é o elemento que provê a regulação necessária para que a criança focalize sua atenção sobre bases e limites dos pontos de vista que formula. Na auto-regulação, em contraste, é a elementos do seu próprio discurso (demandas dialógicas inerentes à argumentação) que a criança responde quando focaliza sua atenção e reflete sobre os fundamentos e limites de seus próprios argumentos. Os variados recursos verbais (perguntas, afirmações, etc.) usados para regular a própria reflexão ou a de outrem, são conceituados como mecanismos semióticos de regulação, num sentido semelhante ao empregado em Wertsch (1978).

\section{"Podemos Falar de Escravidão no Mundo Moderno?" - Análise Ilustrativa}

A pergunta acima explicita o tópico gerador de argumentação no fragmento de discussão que se analisa em seguida. A oposição que aí se estabelece entre Rogério e Lucas, por um lado, e Paula e Márcia, por outro, é desencadeada pela afirmação de Rogério de que, sim, ainda hoje se pode falar de escravidão no Brasil. Os procedimentos analíticos aplicados aos 11 turnos de fala analisados abaixo ilustram o tratamento dado ao conjunto dos dados. Nas transcrições citadas, características das falas dos participantes são preservadas. Breves notas são, entretanto, adicionadas, entre colchetes, com o propósito de aumentar a legibilidade das mesmas. Pontos entre parêntese marcam trechos ininteligíveis. Um T seguido de número identifica turnos de fala. Nomes fictícios foram dados aos alunos. As iniciais PV seguidas de número identificam diferentes pontos de vista surgidos na discussão.

T1. Vilma: "Podemos falar de escravatura no mundo moderno?"

T2. Rogério: "Sim."

T3. Vilma: "Por que?"

T4. Rogério: "Porque ainda é existente no Brasil e em alguns lugares também, sem ser o Brasil."

T5. Lucas: "É porque, por exemplo, [veja os] patrões mesmo: tem uns empregados aí que eles fazem de escravo $(\ldots) "$

T6. Paula: "Rogério disse aí que tem escravatura aqui e alguns outros lugares, mas não é como antigamente, assim..."

T7. Rogério: "É, isso eu sei."

T8. AX: “(. . .) ia pro tronco..."

T9. AY: "É, era 'chiba' [imita som de chicote]."

No que se refere aos movimentos argumentativos dos participantes, dois pontos de vista podem ser identificados entre os turnos T1 e T9 acima. O primeiro $\left(\mathrm{PV}_{1}\right)$ proposto por Rogério, é formulado de um modo explícito e direto que torna desnecessário maiores comentários (T2). No caso de Lucas, embora o ponto de vista permaneça implícito (ver a este respeito Van Eemeren \& Grootendorst,
1992), o conteúdo de sua fala - uma resposta ao "por que?" em T3 - permite que se infira seu alinhamento com o mesmo ponto de vista formulado por Rogério. Diferentes justificativas para este ponto de vista são, entretanto, oferecidas em cada caso. No caso de Rogério, a existência atual de escravidão em diversas partes do mundo justifica seu ponto de vista (T4). Já Lucas parece se apoiar numa espécie de analogia (T5) que lhe permite aplicar certas características definidoras das relação senhor-escravo a certas formas de relação patrão-empregado (sobre argumentos baseados em analogia ver Walton, 1996).

A tomada do turno da fala por Paula, em T6, define seu papel de oponente em relação ao argumento até então proposto. $\mathrm{O}$ enunciado que ela produz tem a força pragmática de contra-argumento em relação ao ponto de vista de Rogério e Lucas - levanta dúvidas quanto à justificativa oferecida pelo último em defesa do ponto de vista de que ainda se pode falar de escravidão no mundo moderno. No entanto, instituir Paula no papel dialético de oponente e trazer para o discurso um elemento explícito de oposição não parecem ser os únicos efeitos gerados em T6. Com este enunciado Paula marca também seu comprometimento com um outro ponto de vista $\left(\mathrm{PV}_{2}\right)$. Embora não conteste a idéia de que é possível falar em escravidão no mundo atual, Paula, no entanto, a qualifica - é de um 'outro tipo' de escravatura que se pode falar hoje em dia. Os enunciados produzidos por AX e AY (alunos não identificados na transcrição) expandem o argumento de Paula. Ambos remetem a fatos que, freqüentes na escravatura da era colonial (castigos, espancamento de escravos), não mais seriam registrados na sociedade contemporânea - o que sustenta, portanto, o ponto de vista de que a escravidão de hoje "não é como antigamente". Que Paula toma estes enunciados como expansões de seu próprio argumento fica claro na retomada de sua da fala em $\mathrm{T} 10$.

A resposta de Rogério, em T 7, sugere uma imediata aceitação do contra-argumento de Paula. Entretanto, é sobretudo o processo reflexivo implicado nesta resposta o que interessa destacar aqui. Nos termos propostos na presente perspectiva, a resposta de Rogério marca a conclusão de um processo reflexivo desencadeado a partir da fala de Paula em T6. Aceitar o contra-argumento de Paula implica retomar afirmações anteriormente feitas (T2, T4) e considerar sua sustentabilidade - o que implica, por sua vez, instituir o próprio pensamento (ponto de vista) como objeto de reflexão.

Quanto à regulação discursiva que opera na argumentação, diferentes modos de regulação podem ser apontados na discussão em análise. Logo no início desta (T2) uma afirmação é feita por Rogério sem que se indique qualquer elemento que lhe dê sustentação. A pergunta de Vilma em T3 surge então como um mecanismo discursivo que regula a busca subseqüente, da parte de Rogério, por elementos com os quais possa apoiar seu ponto de vista. $\mathrm{O}$ mesmo mecanismo parece ter efeito igualmente regulador em relação à busca de Lucas por novos elementos de apoio a $\mathrm{PV}$. Sua fala em $\mathrm{T} 5$ surge como resposta direta à demanda comunicativa de Vilma em T3. O que importa 
ser notado aqui é que, em casos desta natureza, o processo reflexivo que se instala num participante (no caso, Rogério) é implementado por demandas comunicativas oriundas de um outro participante (Vilma). É ainda a ação discursiva de um outro - uma objeção de Paula (T6) ao argumento de Rogério - o que desencadeia no último uma reflexão sobre o limite de seu ponto de vista, reflexão aqui marcada por sua imediata aceitação do contra-argumento (T7).

T10. Paula: "E hoje em dia não, hoje em dia, tudo bem, eles ainda são escravos, modo de dizer, alguns recebem alguma coisa, mas é muito pouco pro... uma diária tem gente que recebe menos de um dólar!"

T11. Márcia: "Eu penso assim, que não é como antigamente agora eles até ganham alguma coisa só que muito pouco, não dá pra eles sobreviverem assim com muito."

Em T10 Paula dá continuidade à comparação entre o "ontem" e o "hoje", iniciada em T8 e T9. O emprego da aditiva "e" marca a incorporação dos enunciados produzidos por AX (T8) e AY (T9) à sua própria posição ("e hoje em dia não"). Neste ponto da discussão, o argumento de aula poderia ser parafraseado nos seguintes termos: a "escravatura" nos tempos modernos "não é como antigamente" já que antes o escravo "ia pro tronco... era chiba (. . .) e hoje em dia não”. O aspecto mais interessante a observar nesse turno é, entretanto, o que surge em seguida. A repetição da expressão "hoje em dia" no início de T10 gera a expectativa de nova expansão do argumento que acaba de ser conjuntamente construído por Paula, AX e AY, uma expansão que agregue novos elementos de contraste entre o ontem e o hoje. O que se segue não oferece, no entanto, qualquer apoio ao ponto de vista de Paula (de que hoje em dia as coisas são diferentes); pelo contrário, o desafia. Com o enunciado que se segue Paula parece antecipar e responder a uma possível objeção ("eles [ainda] são escravos", "tudo bem") ao seu ponto de vista de que o que existe hoje não é "escravatura" de fato. É, portanto, a "voz" de um oponente o que ecoa no discurso de Paula: mesmo não sofrendo violência física, como antigamente, "eles" (trabalhadores não especificados) "ainda são escravos... recebem... mas é muito pouco, não dá pra eles sobreviverem”. Subjacente ao contra-argumento antecipado está uma analogia entre má remuneração pelo trabalho e trabalho escravo cujo efeito é o enfraquecimento de $\mathrm{PV}_{2}$. A reação de Paula ao contra-argumento é de aceitação ("tudo bem”) o que implica, portanto, uma modificação sutil, uma espécie de flexibilização do seu argumento inicial.

Um segundo aspecto - não menos importante - que merece destaque em T10 acima é que aí a dialética de afirmar um ponto de vista, contra-argumentar e responder à oposição aparece na fala de um mesmo indivíduo, caso que ilustra, por excelência, o processo de auto-argumentação e a dinâmica da reflexão auto-regulada de que trata o presente trabalho. Idêntica ocorrência se pode observar em T11. Também aí se pode observar o movimento dialético de afirmar um ponto de vista (a escravatura de hoje "não é como antigamente"), justificá-lo ("agora eles até ganham alguma coisa") e, em seguida, antecipar e reagir a um possível contra-argumento ("só que muito pouco, não dá pra eles sobreviverem”). Também aí a forma assertiva com que Márcia se refere à má remuneração pelo trabalho e à ausência, em sua fala, de qualquer tentativa de refutar o contra-argumento antecipado permitem que se infira a aceitação do mesmo.

Finalmente, no que tange às regulações discursivas focalizadas na presente análise, idênticos modos de regulação podem ser observados nas falas de Paula (T1O) e Márcia (T11). Em ambos os casos, a contra-argumentação desencadeadora de um processo de reflexão (sobre os limites do argumento que ambas defendem) surge de um movimento auto-regulado de antecipação de objeções à posição defendida. Responder ao contra-argumento antecipado só se torna possível a partir de um movimento reflexivo em que Paula e Márcia tomam seus próprios pontos de vista como objetos de reflexão e os (re)avaliam à luz da oposição antecipada. O processo reflexivo aí observado funde-se, portanto, com um processo de auto-argumentação.

\section{Da Regulação pelo Outro à Auto-regulação - Descrição Quantitativa}

$\mathrm{Na}$ terceira e última fase da análise procurou-se investigar se (e em que medida) o engajamento em argumentação favoreceria o incremento de movimentos reflexivos auto-regulados. Para tanto, os percentuais de ocorrência de movimentos reflexivos regulados por outrem e autoregulados foram calculados tomando-se como referência o número total de turnos constituintes da discussão. A hipótese levantada foi a de que, no início da discussão, as crianças tenderiam a refletir sobre as bases e limites de seus pontos de vista em resposta a demandas comunicativas de outros participantes, observando-se posteriormente um gradual incremento na ocorrência de movimentos reflexivos auto-regulados. Os dados descritos na Figura 1 refletem esta tendência.

\section{$\%$}

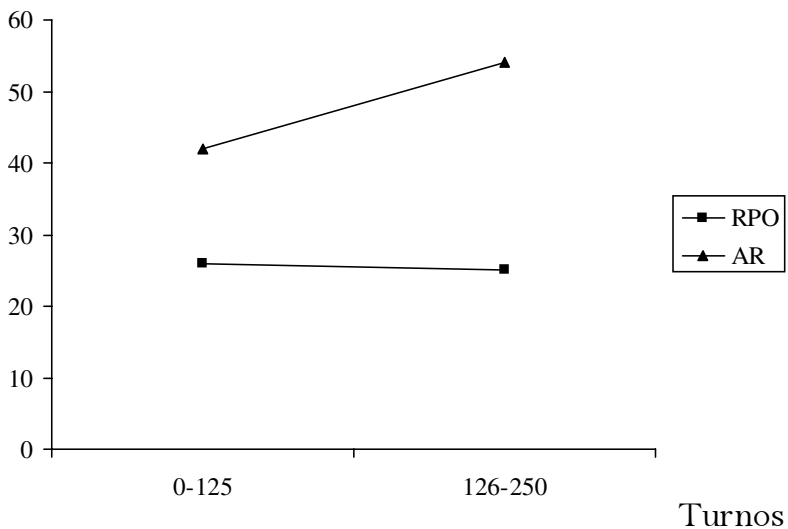

Figura 1. Percentual de movimentos reflexivos regulados por outro (RPO) e auto-regulados (AR) ao longo da discussão. 


\section{Conclusão}

No plano teórico, necessariamente mais abrangente, o presente estudo focalizou relações entre discurso e cognição. De modo mais específico, investigou-se aqui o papel mediador de uma atividade discursiva particular a argumentação - no desenvolvimento do pensamento reflexivo. Embora a relação entre argumentação e reflexão seja há muito reconhecida (ver Piaget, 1923/1999 e Vygotsky, 1931/1995, por exemplo), a natureza desta relação e os mecanismos que a constituem não são de todo compreendidos. O presente trabalho oferece uma perspectiva a partir da qual tais relações podem ser investigadas. $\mathrm{O}$ argumento central proposto foi que os mecanismos semiótico-dialógicos que constituem a argumentação (justificação de pontos de vista, consideração de objeções e reação a elementos contrários) desencadeiam, no indivíduo, um processo de reflexão de natureza metacognitiva. Este argumento se desdobra nas seguintes proposições:

1. A justificação de pontos de vista e a consideração de perspectivas contrárias deslocam a atenção do indivíduo de fenômenos do mundo (objetos do conhecimento sobre os quais argumenta) para os fundamentos e a sustentabilidade de suas concepções sobre aqueles fenômenos (pontos de vista).

2. Este deslocamento implica uma diferenciação nos processos de pensamento a partir da qual não só fenômenos do mundo, mas, também, concepções sobre fenômenos do mundo tornam-se objetos de reflexão. "Pensar sobre o mundo" e "pensar sobre as próprias concepções a respeito do mundo", argumentou-se, remetem a diferentes níveis de semiotização do pensamento humano.

3. O metaprocesso que possibilita ao indivíduo refletir sobre bases e limites de suas concepções a respeito de objetos e fenômenos do mundo pode ser conceituado como um processo de auto-argumentação - desencadeada pelo indivíduo e endereçada às suas próprias posições.

4. Ontogeneticamente, a auto-argumentação emerge em situações nas quais justificação de posições e exame de idéias contrárias ocorrem inicialmente como resposta à demanda direta de outros. A necessidade comunicativa de tornar as próprias posições aceitáveis, em face à existência de perspectivas contrárias, dá ao indivíduo o impulso de que ele precisa para passar da argumentação regulada por outro à auto-argumentação.

Neste trabalho propôs-se ainda um procedimento analítico desenhado para capturar o desenvolvimento da autoargumentação. Inicialmente argumentos, contra-argumentos e respostas a contra-argumentos são identificados nas falas dos participantes. Em seguida distinguem-se:

1. Argumentos/contra-argumentos suscitados por outros dos espontaneamente produzidos.

2. Contra-argumentos que focalizam argumentos de outros dos que antecipam críticas aos argumentos do próprio falante.
3. Finalmente, a freqüiência dos elementos identificados na fase anterior é observada em diferentes momentos da discussão (início, fim). A aplicação deste procedimento à argumentação de crianças em ambiente de sala de aula, sem intermediação da professora, mostrou que ao progresso da discussão correspondeu uma produção crescente de movimentos argumentativos/ reflexivos auto-regulados. Este resultado é interpretado como indicativo do potencial da argumentação no incremento do controle e da reflexão voluntária sobre fundamentos/limites do próprio conhecimento.

\section{Referências}

Bakhtin, M., \& Volochinov, V. N. (1995). Marxismo e filosofia da linguagem. São Paulo, SP: Hucitec. (Original publicado em 1929-1930)

Bakhurst, D. (2002). A memória social no pensamento soviético. In H. Daniels (Eds.), Uma introdução a Vygotsky (pp. 229254). São Paulo, SP: Loyola.

Billig, M. (1987). Arguing and thinking: A rhetorical approach to social psychology. Cambridge, UK: Cambridge University Press.

Flavell, J. H. (1987). Speculations about the nature and development of metacognition. In F. Weinert \& R. Kluwe (Eds.), Metacognition, motivation, and understanding (pp. 21-29). Hillsdale, NJ: Erlbaum.

Kuhn, D. (2000). Metacognitive development. In L. Balter \& C. S. Tamis-Le Monda (Eds.), Child psychology: A handbook of contemporary issues (pp. 259-286). Philadelphia, PA: Psychology Press.

Leitão, S. (2000). The potential of argument in knowledge building. Human Development, 6, 332-360.

Leitão, S. (2001, September). Analyzing changes in view during argumentation: A quest for method [Eletronic version]. Forum Qualitative Sozialforschung/Forum: Social Research, 2(3). Retirado de http://qualitative-research.net/fqs/fqs-eng.htm.

Leitão, S. (2002). Self-argumentation: The rhetorical dimension of meta-cognition. Trabalho apresentado nos Clark 'Kitchen Seminars', Clark University, Worcester, MA.

Leitão, S. (no prelo). La dimensión epistémica de la argumentación. In E. Kronmuiller \& C. Cornejo (Eds.), Ciencias de la mente: aproximaciones desde Latinoamamérica. Santiago, Chile: JCSáez Editor.

Linnel, P. (1998). Approaching dialogue: Talk, interaction and contexts in dialogical perspectives. In K. Malmkjaer (Ed.), Studies in language and society: Vol. 3. Amsterdam, Netherlands: John Benjamins.

Martí, E. (1995). Metacognición: entre la fascinación y el desencanto. Infancia y Aprendizaje, 72, 9-32

Mead, G. H. (1972). Mind, self, and society. From the standpoint of a social behaviorist. Chicago: The University of Chicago Press. (Original publicado em 1934)

Medvedev, P. N. (1985). The formal method in literary scholarship: A critical introduction to sociological poetics. Cambridge, MA: Harvard University Press. (Original publicado em 1928)

Morato, E. M. (1996). Linguagem e cognição: As reflexões de L. S. Vygotsky sobre a ação reguladora da linguagem. São Paulo, SP: Plexus.

Piaget, J. (1999). A linguagem e o pensamento da criança. São Paulo, SP: Martins Fontes. (Original publicado em 1923) 
Rommetveit, R. (1992). Outlines of a dialogically based socialcognitive approach to human cognition and communication. In A. H. Wold (Ed.), The dialogical alternative: Towards a theory of language and mind (pp. 19-44). Oslo, Noruega: Scandinavian University Press.

Valsiner, J., \& Van der Veer, R. (2000). The social mind: Construction of the idea. Cambridge, UK: Cambridge University Press.

Van Eemeren, F. H., \& Grootendorst, R. (1992). Argumentation, communication, and fallacies. A pragma-dialectical perspective. Hillsdale, NJ: Erlbaum.

Van Eemeren, F. H., Grootendorst, R., Henkemans, F. S., Blair, J. A., Johnson, R. H., Krabbe, E. C. W., Plantin, C., Walton, D. N., Willard, C. A., Woods, J., \& Zarefsky, D. (1996). Fundamentals of argumentation theory: A handbook of historical backgrounds and contemporary developments. Mahwah, NJ: Erlbaum.

Vygotsky, L. S. (1995). Historia del desarrollo de las funciones psíquicas superiores. In A. Alvarez \& P. Del Río (Eds.), Obras escogidas: Vol. 3. Problemas del desarrollo de la psique (pp. 7-340). Madrid, España: Visor. (Original publicado em 1931)

Vygotsky, L. S. (2001). A construção do pensamento e da linguagem. São Paulo, SP: Martins Fontes. (Original publicado em 1934)

Walton, D. N. (1996). Argumentation schemes for presumptive reasoning: Mahwah, NJ: Erlbaum.

Wertsch, J. V. (1978). Adult-child interaction and the roots of metacognition. Quarterly Newsletter of the Institute for Comparative Human Development, 1, 15-18.

Wertsch, J. V. (Ed.). (1988). Culture, communication, and cognition. Cambridge, UK: Cambridge University Press.

Wertsch, J. V., Del Río, P., \& Alvarez, A. (1995). Sociocultural studies of mind. Cambridge, UK: Cambridge University Press. 